\title{
Estudos pós-coloniais e educação: diálogos com o currículo escolar e as relações étnico-raciais ${ }^{1}$
}

\author{
Estudios post-coloniales y educación: diálogos com El currículo escolar y \\ lãs relaciones étnico-raciales
}

\section{Postcolonial studies and education: dialogues with the school curriculum and ethnic-racial relations}

\author{
Cledinea Carvalho Santos ${ }^{2}$ \\ Wesley Santos de Matos $^{3}$ \\ Benedito Eugenio ${ }^{4}$
}

\begin{abstract}
Resumo
O século XX foi cenário de transformações políticas, econômicas e social em todo o planeta. Essas mudanças culminaram na fragmentação e dissipação das culturas no âmbito do multiculturalismo e a multipolarização do mundo. Isto surge na contramão do imperialismo bipolar eurocêntrico até então vigente. As mudanças emergentes muito têm a ver com a descolonização da África e Ásia, seguido da migração e diáspora destes povos após a Segunda Guerra Mundial. Este fato resultou em mudanças drásticas no cenário internacional e ficou conhecido como período pós-colonial. Tais acontecimentos propiciaram produções teóricas voltadas para o novo contexto e análises críticas ao velho modelo colonial. Isto tomou forma dando origem a nova corrente teórica, o Pós-colonialisimo. Para os teóricos dessa corrente, o Pós-colonialismo propõe descolonizar o pensamento a partir da crítica ao modelo imperialista eurocentrado numa nova concepção de produção epistemológica do Sul para O sul. Nesse sentido, o Pós-colonialismo, ao considerar como relevante os saberes subalternos, contribui para problematizarmos a hierarquização de saberes presentes no currículo escolar, tanto o prescrito quanto o praticado. O estudo da História e Cultura Afro-brasileira e indígena na escola ainda tem se constituído como um desafio, pois as Leis 10.639/03 e 11.645/08 questionam a lógica hegemônica de uma cultura comum e impõem a necessidade de questionamento das práticas pedagógicas e curriculares que silenciam saberes de diferentes grupos presentes no interior da escola. Este artigo aborda as discussões acerca das possibilidades trazidas pelas teorias pós-coloniais para pensarmos a educação das relações étnico-raciais e a educação escolar indígena. Tomamos como base, para isso, as contribuições de Boaventura Santos, Anibal Quijano, Catherine Waslh, Vera Candau. Procuramos apontar de que maneira essas teorias contribuem para a pesquisa em currículo e a diversidade étnica, tal como proposto pelas Leis 10639/03 e 11645/08.
\end{abstract}

\footnotetext{
${ }^{1}$ Artigo apresentado no Simpósio Temático Relações étnico-raciais na América Latina: debates interseccionais na diáspora durante o II Seminário Latino-Americano de Estudos em Cultura - SEMLACult em Foz do Iguaçu/PR, Brasil, 2018.

${ }^{2}$ Mestre em Cultura e Sociedade pela Universidade Federal da Bahia - UFBA. Professora na Rede Municipal de
Ensino de Jaguaquara-Ba. Jaguaquara, Bahia, Brasil. E-mail: $\underline{\text { keucarvalho@ @ahoo.com.br }}$

${ }^{3}$ Mestre em Relações Étnicas e Contemporaneidade pela Universidade Estadual do Sudoeste da Bahia - UESB. Professor de História da Rede Estadual da Bahia. Jaguaquara, Bahia, Brasil. E-mail: wesleyxdmattos@hotmail.com

${ }^{4}$ Doutor em Educação pela Universidade de Campinas - UNICAMP. Docente da Universidade Estadual do Sudoeste da Bahia (UESB) e do Programa de Pós-graduação em Ensino (PPGEn). Vitória da Conquista, Bahia, Brasil. E-mail: beneditoeugenio@bol.com.br
} 
Palavras-chave: Currículo; Estudos Pós-coloniais; Relações étnico-raciais.

\title{
Resumen
}

El siglo XX fue escenario de transformaciones políticas, económicas y sociales en todo el planeta. Estos cambios culminaron en la fragmentación y disipación de las culturas en el ámbito del multiculturalismo y la multipolarización del mundo. Esto surge en contra del imperialismo bipolar eurocéntrico hasta entonces vigente. Los cambios emergentes tienen mucho que ver con la descolonización de África y Asia, seguida de la migración y la diáspora de estos pueblos después de la Segunda Guerra Mundial. Este hecho resultó en cambios drásticos en el escenario internacional y se conoció como período post-colonial. Tales acontecimientos propiciaron producciones teóricas dirigidas al nuevo contexto y análisis críticos al viejo modelo colonial. Esto tomó forma dando origen a la nueva corriente teórica, el Pos-colonialismo. Para los teóricos de esta corriente, el Poscolonialismo propone descolonizar el pensamiento a partir de la crítica al modelo imperialista eurocentrado en una nueva concepción de producción epistemológica del Sur hacia el sur. En ese sentido, el post-colonialismo, al considerar como relevante los saberes subalternos, contribuye a problematizar la jerarquización de saberes presentes en el currículo escolar, tanto lo prescrito como lo practicado. El estudio de la Historia y Cultura Afrobrasileña e indígena en la escuela todavía se ha constituido como un desafío, pues las Leyes 10639/03 y 11645/08 cuestionan la lógica hegemónica de una cultura común e imponen la necesidad de cuestionamiento de las prácticas pedagógicas y curriculares que silencian saber de diferentes grupos presentes en el interior de la escuela. Este artículo aborda las discusiones acerca de las posibilidades traídas por las teorías postcoloniales para pensar la educación de las relaciones étnico-raciales y la educación escolar indígena. Tomamos como base, para ello, las contribuciones de Boaventura Santos, Anibal Quijano, Catherine Waslh, Vera Candau. Se busca apuntar de qué manera esas teorías contribuyen a la investigación en currículo y la diversidad étnica, tal como propone las Leyes 10.639/03 y 11.645/08.

Palabras claves: Plan de estudios; Estudios Pos-coloniales; Relaciones étnico-raciales.

\begin{abstract}
The twentieth century was the scene of political, economic and social transformations across the planet. These changes culminated in the fragmentation and dissipation of cultures in the context of multiculturalism and the multipolarization of the world. This arises against the prevailing Eurocentric bipolar imperialism. The emerging changes have much to do with the decolonization of Africa and Asia, followed by the migration and diaspora of these peoples after World War II. This resulted in drastic changes in the international scene and became known as the postcolonial period. Such events provided theoretical productions focused on the new context and critical analyzes of the old colonial model. This took shape giving rise to the new theoretical current, the Postcolonialism. For theorists of this current, Postcolonialism proposes to decolonize the thought from the critique of the Eurocentric imperialist model in a new conception of epistemological production from the South to the South. In this sense, postcolonialism, considering as relevant the subaltern knowledge, contributes to problematize the hierarchy of knowledge present in the school curriculum, both prescribed and practiced. The study of Afrob-Brazilian and indigenous history and culture in the school has still been a challenge, since Laws $10639 / 03$ and 11645/08 question the hegemonic logic of a common culture and impose the need to question pedagogical and curricular practices that silence the knowledge of different groups present inside the school. This article discusses the discussions about the possibilities brought by postcolonial theories to think about the education of ethnic-racial relations and indigenous school education. For this, we take the contributions of Boaventura Santos, Anibal Quijano, Catherine Waslh, Vera Candau. We seek to point out how these theories contribute to curriculum research and ethnic diversity, as proposed by Laws 10639/03 and 11645/08.
\end{abstract}

Keywords: Curriculum; Postcolonial Studies; Ethnic-racial relations.

\section{Introdução}

O século XX foi cenário de transformações políticas, econômicas e social em todo o planeta. Estas mudanças culminaram na fragmentação e dissipação das culturas e a 
multipolarização do mundo, em contraposição ao imperialismo eurocêntrico até então vigente. As mudanças emergentes muito têm a ver com a descolonização da África e Ásia, seguidas da migração e diáspora destes povos após a Segunda Guerra Mundial. Este fato resultou em mudanças drásticas no cenário internacional e ficou conhecido como período pós-colonial. Tais acontecimentos propiciaram produções teóricas voltadas para o novo contexto e análises críticas ao velho modelo colonial, a exemplo das abordagens pós-coloniais, decoloniais, intermulticulturais, os estudos culturais.

Autores como Enrique Dussel, Walter Mignolo, Aníbal Quijano, Catherine Walsh, Ramón Grosfoguel, Santiago Castro-Goméz, Edgar Lander, Arturo Escobar, Nelson Maldonado-Torres, tem contribuído, com seus escritos, para o questionamento das diferentes formas de opressão postas em práticas contra os grupos subalternos.

No Brasil, Paulo Freire, em diferentes obras, já nos chamava a atenção sobre as consequências da opressão colonial, sendo considerado por muitos estudiosos como antecessor do debate da decolonialidade na América Latina, principalmente ao levarmos em consideração sua proposta de educação popular. Autores como Ivanilde Apoluceno de Oliveira, Vera Candau, Nilma Lino Gomes, Petronilha Beatriz, Ana Ivenick têm dado importantes contribuições para entendermos as questões inter/multi/pós-coloniais.

O Pós-colonialisimo, enquanto perspectiva conceitual, analisa a imposição dos países colonizadores sobre os outros povos, os colonizados, numa construção ideológica da subalternização em detrimento dos ditos superiores e desenvolvidos intelectualmente e culturalmente.

Para os teóricos desta corrente, o Pós-colonialismo propõe descolonizar o pensamento por meio da crítica ao modelo imperialista eurocentrado numa nova concepção de produção epistemológica do Sul para o Sul, pois até então as relações entre os povos subalternizados e os colonizadores foi uma relação de poder do modelo hegemônico.

O envolvimento de vários intelectuais na luta pelo fim da dominação colonial possibilitou a produção de conhecimento que levou as reflexões das consequências da política imperialista sobre os povos dominados e assim fortalecer as bases democráticas da sociedade. Este artigo, de natureza bibliográfica, aborda as discussões acerca das possibilidades trazidas pelas teorias pós-coloniais para pensarmos a educação das relações étnico-raciais e a educação escolar indígena.

A metodologia empregada para a discussão foi do tipo bibliográfica. A revisão bibliográfica constitui a primeira etapa de qualquer pesquisa. Segundo Boccato (2006, p.266): 


\begin{abstract}
a pesquisa bibliográfica busca a resolução de um problema (hipótese) por meio de referenciais teóricos publicados, analisando e discutindo as várias contribuições científicas. Esse tipo de pesquisa trará subsídios para o conhecimento sobre o que foi pesquisado, como e sob que enfoque e/ou perspectivas foi tratado o assunto apresentado na literatura científica. Para tanto, é de suma importância que o pesquisador realize um planejamento sistemático do processo de pesquisa, compreendendo desde a definição temática, passando pela construção lógica do trabalho até a decisão da sua forma de comunicação e divulgação.
\end{abstract}

O levantamento bibliográfico foi importante para identificarmos os principais autores que vem discutindo o pós-colonialismo no campo educacional.

\title{
Educação das relações étnico-raciais e educação
}

O Brasil, enquanto nação, convive com o racismo enraizado em seu tecido social. Entre nós se construiu um pensamento racial extremamente sofisticado a partir da segunda metade do século XIX e que serviu de base para justificar as desigualdades existentes até hoje entre negros e brancos- o racismo científico-, principalmente com as contribuições adivinhas das escolas de Direito (Bahia, Recife, São Paulo) e Medicina (Bahia e Rio de Janeiro). Temos nas obras de Nina Rodrigues a expressão máxima dessa perspectiva.

Para Guimarães (2004, p.10), “O racismo surge, portanto, na cena política brasileira, como doutrina científica, quando se avizinha a abolição da escravatura e, consequentemente, a igualdade política e formal entre todos os brasileiros, e mesmo entre estes e os africanos escravizados".

Ao longo do século XX, principalmente a partir dos anos 1930, diferentes construções teóricas e interpretações contribuíram para que elaborássemos nosso sentido de nação e de povo. A mistura de raças, até então considerada negativa para a construção da nação, passa a ser vista/pensada de forma positiva. Gilberto Freyre, com seus escritos sociológicos, particularmente em Casa Grande e Senzala, retira a miscigenação de seu aspecto biológico e passa a interpretá-la de uma perspectiva cultural. De acordo com Guimarães (2004, p.12), “Gilberto Freyre promove uma verdadeira revolução ideológica no Brasil moderno ao encontrar na velha, colonial e mestiça cultura luso-brasileira nordestina a alma nacional".

Essa situação de convivência pacífica entre as raças será o motivador para o projeto Unesco, nos anos 1950. O Brasil passa a ser visto como um laboratório para o estudo das 
relações raciais. A publicação dos primeiros resultados desse projeto institucionaliza a Sociologia das Relações Raciais entre nós e também aponta para a falácia da democracia racial tão defendida por intelectuais brasileiros no começo do século XX. Estudos como os efetuados por Florestan Fernandes, Oracy Nogueira, Octávio Ianni, Virgínia Bicudo, Fernando Henrique Cardoso, Thales de Azevedo, ao valerem-se de diferentes referenciais teórico-metodológicos, contribuíram em muito para isso.

É a partir dos anos 1970 que novos elementos são empregados para o estudo das relações raciais no Brasil, a exemplo da articulação raça e desigualdades, principalmente nos campos da educação e do trabalho. Raça deve ser entendida como construção social (GUIMARÃES, 2003). Da perspectiva sociológica com a qual trabalhamos, defendemos que raça ainda é um conceito importante para o estudo das relações sociais/identidades sociais; raça é compreendida como um discurso que produz o sujeito/objeto sobre o qual se fala e produtora, assim, do racismo.

Dessa forma, o racismo pode ser compreendido como um discurso, ou seja, "Um conjunto de regras anônimas, históricas, sempre determinadas no tempo e espaço, que definiram em uma dada época e para uma área econômica, social, geográfica ou linguística dada, as condições de exercício da função enunciativa" (FOUCAULT, 1997, p.43).

Os discursos racistas estão presentes em várias instâncias/instituições sociais e artefatos. A escola, como espaço social produtor de discursos das mais variadas ordens, também corrobora nesse processo.

Conforme pontua Gonçalves e Silva (2007, p.490), a educação das relações étnicoraciais tem por finalidade "a formação de cidadãos, mulheres e homens empenhados em promover condições de igualdade no exercício de direitos sociais, políticos, econômicos, dos direitos de ser, viver, pensar, próprios aos diferentes pertencimentos étnico-raciais e sociais".

Por isso no interior das escolas é importante que os processos de ensino e aprendizagem abordem, nas mais diversas disciplinas curriculares, todos os grupos raciais presentes na sociedade brasileira a fim de que os discentes tomem consciência do processo de racialização pelo qual nosso país passou e de como os saberes ensinados sempre privilegiaram um único grupo étnico, os brancos. A nação brasileira se projetou como branca e isso contribuiu para que os saberes dos negros e indígenas não fossem ensinados na escola, pois 
"pessoas criadas numa sociedade racializada têm uma visão de mundo marcada por essa racialidade" (BENTO, 2002, p. 48).

Nisso reside a contribuição das Leis 10639/03 e 11645/08. Estas leis representam um importante marco na história da educação brasileira. Por meio delas, ações de combate ao racismo ganham revigorado fôlego no contexto escolar. As regulamentações da inclusão de temáticas da história afro-brasileira e indígena encarnam um desejo de longa data. A ideia de se trabalhar as diferenças raciais nas escolas como fator agregador e gerador de saberes advêm de mobilizações no decorrer da história brasileira.

Ter uma política curricular que vise ao reconhecimento da história e cultura africana na constituição da sociedade brasileira é um grande avanço. Certamente, uma das forças que corroborou para essa conquista foi o Movimento Negro. Esse movimento agiu e age como um "produtor de saberes emancipatórios e um sistematizador de conhecimentos sobre a questão racial no Brasil. Saberes transformados em reivindicações, das quais várias se tornaram políticas de Estado nas primeiras décadas do século XXI” (GOMES, 2017, p. 14).

Alcançar uma concepção crítica incorporada à pedagogia brasileira ainda não é uma tarefa simples. Conquistas assim resultam de situações favoráveis e adversas decorrentes do viés político em vigor em determinado momento histórico. O exemplo do Brasil, com uma história marcada pelo multiculturalismo, os desafios em lidar com as "relações interétnicas tem sido uma constante através de toda a sua história, uma história dolorosa e trágica principalmente no que diz respeito aos grupos indígenas e afrodescendentes" (MOREIRA; CANDAU, 2008, p. 17).

Conforme Gomes (2017, p.15) no decorrer da maior parte da história brasileira os "setores conservadores de direita, os ruralistas e os capitalistas", interferem nas relações sociais provocando ainda mais desigualdades, discriminações e racismo. Os ranços provenientes dessa comunicação conflituosa culminam em atos de opressão nas mais variadas esferas da vida humana.

As ações pedagógicas que historicamente compuseram o currículo das escolas brasileiras tiveram como base o pensamento eurocêntrico de matriz colonizadora. Pensar as relações sociais pelo viés eurocêntrico é caminhar no sentido da invisibilização de todas as demais culturas que dela difere. Tal postura no ambiente escolar corrobora com a 
disseminação de representações hegemônicas que fortalecem pensamentos discriminatórios. Essas categorizações espelham uma relação de poder que hierarquiza e exclui seguindo a lógica do poder dominante.

Para lidar com questões das representações hegemônicas no cotidiano escolar primeiramente se faz necessário ter a clareza de "que as diferenças são construídas socialmente e que, subjacente a elas, encontram-se relações de poder" (MOREIRA; CANDAU, 2008, p. 44). Vertentes de pensamentos sociais que trabalham para a desconstrução de saberes enviesado buscam encontrar nas diferenças inerentes aos seres humanos, uma base reflexiva no processo educativo. Respaldada nessa lógica, surgem possibilidades pedagógicas para se construir uma educação que leve em consideração as diferenças.

\title{
Pós-colonialismo e educação das relações étnico-raciais
}

O Pós-colonialisimo na concepção de Boaventura de Sousa Santos (2010), segue a lógica da supremacia da raça para justificar a dominação:

\begin{abstract}
A relação de dominação é a consequência e não a causa dessa hierarquia e pode ser mesmo considerada como uma obrigação de quem é classificado como superior (por exemplo, o «fardo do homem branco» em sua missão civilizadora). Embora as duas formas de classificação (raça e sexo) sejam decisivas para que a relação capital/trabalho se estabilize e se difunda globalmente, a classificação racial foi a mais profundamente reconstruída pelo capitalismo(...). De acordo com esta lógica, a não-existência é produzida sob a forma de inferioridade insuperável porque natural. Quem é inferior, porque é insuperavelmente inferior, não pode ser uma alternativa credível a quem é superior (SANTOS, 2010, p. 13).
\end{abstract}

Por isso, pensar o mundo fora da lógica civilizatória é imprescindível para a construção de ideologias de libertação e consciente de uma indefensável moral europeia com seu projeto de supressão da dignidade dos outros povos, especialmente os negros. Em síntese, a proposta pós-colonial consiste na tomada de consciência do que foi o projeto civilizatório e desse modo construir uma nova sociedade.

Já os estudos Decoloniais em congruência à crítica ao modelo colonial, apontam a perspectiva da imposição do pensamento hegemônico na América-latina. Seguindo a lógica de que o poder se relaciona com o conhecimento, os teóricos desta corrente abordam discussões da dominação sofrida pelos povos originários a partir da conquista e colonização europeia. E por isso, nossa forma de produzir conhecimento é herdada da cultura europeia e isto implica em práticas culturais da matriz colonial implicando em processos 
discriminatórios e de subjugação.

Tal estrutura tem servido não apenas para envelopar a humanidade e a condição humana em ideias lineares de civilização e progresso, mas também enlaçar a modernidade na sua base: a colonialidade, isto é, uma fonte global de poder que classificou hierarquicamente populações, seu conhecimento e seus sistemas de vida cosmológica, de acordo com o padrão europeu (WALSH, 2010, p.1).

Os intelectuais decoloniais tratam principalmente da manutenção da colonialidade ainda na contemporaneidade nas mais diversas modalidades e níveis, seja na política, na economia ou na cultura, no qual tudo que fazemos e dizemos é provido dos discursos da dominação implicando em condutas discriminatórias aos povos originários e ou escravizados.

Sinteticamente, ambas as correntes de pensamento têm em comum a experiência da colonização do Ocidente sobre o resto do mundo, especialmente, Ásia, África e Américalatina que sofreram violações de direitos como: a servidão, dizimação, violência e dominação. A leitura de autores como Walsh (2010, Quijano (2005), Achinte (2006), Freire (1987), Bhabha (1998), Galceran Huguet (2016), Candau (2016) em muito contribui para o entendimento das contribuições do pós-colonialismo para a pesquisa em educação.

Assim, sendo a escola local onde a diversidade se faz presente em todas as suas manifestações, se torna ambiente propício para se combater a discriminação historicamente construída sobre os povos indígenas e africanos que foram trazidos para o Brasil em condição de escravos e transformados em "coisas".

Ao longo de todo o processo educacional brasileiro o currículo escolar sempre enalteceu a história do colonizador negando a existência de outras vozes que ao contrário do que se ensinou, nem o índio e nem o negro aceitaram as condições as quais foram submetidos. $\mathrm{Na}$ verdade, tornaram-se protagonistas em vários os momentos criando as mais diversas formas de resistências.

A escola como salvaguarda da estruturação do conhecimento tem a obrigação de buscar implementar no seu currículo - conforme orienta a lei - as histórias que não foram ouvidas e que quando foram contadas se fez de forma a reafirmar estereótipos a partir das diferenças raciais/culturais/históricas e fomentar preconceitos, colocando o negro e o índio sempre como o subalterno, o vencido, o subserviente, o selvagem. Portanto, precisamos contribuir para amenizar os danos causados a estes povos.

Mediante o exposto, descolonizar o que se sabe sobre estes povos possibilita o acesso ao conhecimento multicultural e multieconômico, apresentando suas grandezas, invenções e 
conquistas e a instituição escolar possui ferramentas capazes de estruturar este conhecimento quando reconhece as diferenças não como algo a ser combatido, mas a ser compartilhado.

A Lei 10.639/03 é uma vitória do movimento negro na luta pela decolonização da educação formal em prol do combate ao racismo, da não folclorização da cultura, pelo respeito à diversidade. Isto não significa negar a outra história, mas a de apresentar outras histórias e outros sujeitos, outros feitos e as formas de lutas e resistências.

Assim, a Lei citada constitui-se como uma política pública de ação afirmativa para a população negra, que dentre outros aspectos visa romper com a monocultura instituída historicamente no espaço escolar (OLIVEIRA, 2014; GOMES, 2012; SILVA \& MARQUES, 2016) e determina profunda mudança curricular na educação básica em nível nacional. Cabe também ao Estado otimizar, nos espaços escolares, políticas curriculares que respeitem as diferenças e os diferentes, em consonância com a referida Lei e suas diretrizes operacionais.

Nessa perspectiva, Candau (2003, p.24) aponta que "o cotidiano da escola é palco de diferentes relações sociais e reflete a diversidade cultural presente na sociedade, assim como diferentes visões de mundo, estilos de vida, crenças, costumes, cores e etnia".

Diante das demandas que emanam dessa diversidade, a escola é chamada a assumir a responsabilidade de assegurar que todos os conhecimentos construídos por grupos minoritários também sejam inseridos na estrutura curricular, rompendo com a visão hegemônica historicamente construída (GOMES, 2012). No entanto, a educação para a diversidade, mesmo assentada em forte base legal, ainda encontra inúmeras dificuldades para se concretizar nos espaços escolares.

Durante um longo período o currículo foi pensado sob o pensamento eurocêntrico contribuindo para práticas racistas em relação aos negros refletidas nas escolas. Em muitos casos, isso é decorrente da formação deficitária de professores e do desconhecimento geral da história dos africanos e do negro no Brasil (SILVA, 2007).

Sobre tais questões, Silva e Marques (2016) apontam que:

[...] a implantação da educação para as relações étnico-raciais nas escolas públicas ainda precisam vencer muitos obstáculos para a sua efetivação, podendo ser estes sintetizados em dois pontos principais: $1^{\circ}$ - Formação inicial e continuada de professores, que possibilite uma visão reflexiva sobre a diversidade, contribuindo para a habilitação de profissionais com qualidade, minimizando qualquer espécie de preconceito presente na prática dos educadores, e por consequência, no espaço escolar; $2^{\circ}$ - Apoio institucional/estatal através do fornecimento de subsídios e materiais de apoio que dê possibilidades para os profissionais da educação de executar ações básicas para se trabalhar conceitos referentes à diversidade e sua relação social (SILVA \& MARQUES, 2016, p. 15-16). 
Conforme Silva (2007), as dificuldades para a implantação dessas políticas curriculares que visam à descolonização do currículo devem muito mais à história das relações étnico-raciais no Brasil e aos processos educativos que elas desencadeiam, consolidando preconceitos e estereótipos, do que a procedimentos pedagógicos ou a tão reclamada falta de textos e materiais didáticos.

Inserir os conteúdos previstos na Lei 10.639/03 implica em mudanças profundas na política curricular em todos os níveis e esferas da educação. No entanto, para se efetivar em bases sólidas nas escolas, lugar onde realmente a mudança precisa acontecer, é preciso investimento em formação continuada de professores, já que "os professores alegam pouco preparo para abordar questões que tratam de discriminação, preconceitos, diferenças culturais, em sala de aula" (GOMES, 1999, p. 89).

Se pretende com as discussões decoloniais e pós-coloniais, na educação, um ensino multirreferencial, onde os sujeitos ensinem e aprendam, afetem e sejam afetados, pois "o espectador também age, tal como o aluno ou o intelectual. Ele observa, seleciona, compara, interpreta" (RANCIÈRE, 2010, p. 17). Embora o autor tenha dito isto ao tratar da arte, é pertinente ao propósito deste artigo, porque é preciso insistentemente construir uma relação dialógica na produção do conhecimento para aprendizagem emancipadora do sujeito, pois como nos disse Paulo Freire (1987, p. 68) "não há saber mais, nem saber menos, há saberes diferentes".

\section{Considerações finais}

Propomos neste artigo diálogos necessários para compreensão da importância das Leis 10639/03 e 11.645/08 no campo da educação formal no intuito de se combater o preconceito contra os afro-brasileiros, os povos indígenas e os africanos. Ao tornar obrigatório o ensino da história e cultura desses povos, estas leis tornam-se uma política de ação afirmativa e modificam a relação histórica de invisibilidade dos conhecimentos e saberes dos povos ancestrais nos currículos da educação básica.

Evidentemente que as alterações trazidas pelas Leis 10639/03 e 11.645/08 sacudiram diretamente a estrutura racista da sociedade brasileira. Isso se evidenciou nas dificuldades e dilemas para seu cumprimento mediante as resistências dos educadores em promovê-la.

Salientamos, portanto, que ao apontarmos as dificuldades e dilemas não é no sentido de fazer juízo de valor as resistências dos professores e professoras, mas de corroborar para uma formação docente que descolonize o pensamento a partir de uma história não linear e a 
inclusão dos currículos ocultos no planejamento escolar e desse modo explorar o pensamento crítico.

Ao trazermos as considerações do pensamento pós-colonial/decolonial, propusemos repensar a educação e fomentar as discussões que viabilizem uma educação não colonizante conforme nos foi imposto desde o início aos dias atuais e que gire em torno de uma práxis pedagógica para o desmonte das grandes narrativas historicizantes.

Essa premissa colabora para o tombamento das categorias estigmatizadoras e para o vicejar de uma nova era para educação no qual os sujeitos possam falar e serem ouvidos e construam,juntos, uma sociedade descentralizadora das ideias, dos saberes, enfocando a perspectiva da diferença cultural como possibilidades para o convívio respeitoso entre todos em um processo de integração.

Na seara da educação, decolonizar é urgente, mas só será possível em um movimento revolucionário de proposição dialógica entre a lei, as subjetividades professorais e as epistemologias decoloniais para o desenredar das diferenças.

\section{Referências}

ACHINTE, Adolfo Alban. Conocimiento y lugar: más allá de la razón hay un mundo de colores. Texiendo Textos. Cinco Hilos Para Pensar Los Estudios Culturales, La Colonialidad Y La Interculturalidad . Colombia: Ed. Ediorial Universidad Del Cauca, 2006.

BARBOSA, Joaquim Gonçalves. Multirreferencialidade e produção do conhecimento. Revista Educação em Questão, Natal, v. 32, n. 18, p. 209-223, maio/ago. 2008.

BENTO, Maria A. da S. Racialidade e produção do conhecimento. In: SEYFERTH et al. Racismo no Brasil. São Paulo: ABONG, Ação Educativa, ANPED, 2002.

BHABHA, Homi K. O pós-colonial e o pós-moderno. In: O local da cultura. Belo Horizonte: Editora da UFMG, 1998.

BOCCATO, V. R. C. Metodologia da pesquisa bibliográfica na área odontológica e o artigo científico como forma de comunicação. Rev. Odontol. Univ. Cidade São Paulo, São Paulo, v. 18, n. 3, p. 265-274, 2006.

CANDAU, Vera Maria. Somos tod@s iguais? Rio de Janeiro: DP\&A, 2003.

, Vera (Org.). Interculturalizar, descolonizar, democratizar: uma educação outra? Rio de Janeiro: 7 Letras, 2016.

FOUCAULT, Michel. A arqueologia do saber. Rio de Janeiro: Forense Universitária, 1997.

FREIRE, Paulo. Pedagogia do oprimido. 17. ed. Rio de Janeiro: Paz e Terra, 1987. 
GONÇALVES E SILVA, Petronilha B. Aprender, ensinar e relações étnico-raciais no Brasil. Revista Educação, vol.63, n.03, p. 498-506, 2007.

GUIMARÃES, Antonio S. Preconceito de cor e racismo no Brasil. Revista de Antropologia, vol.47, n.01, p. 09-43, 2004.

2003.

. Como trabalhar com "raça" em Sociologia. Educação e Pesquisa, vol.29, n.01, p. 93-107,

GALCERAN HUGUET, Montserrat, "La novedad de lo postcolonial." In: . $L a$ bárbara Europa. Una mirada desde el postcolonialismo y la descolonialidad, Madrid: Traficantes de Sueños, 2016.

GOMES, Nilma Lino. Relações Étnico-Raciais, Educação e Descolonização dos Currículos. Currículo Sem Fronteiras, v.12, n.1, p. 98-109, Jan/Abr 2012.

Educação e relações raciais: discutindo algumas estratégias de atuação. In: MUNANGA, Kabengele (Org.). Superando o racismo na escola. Brasília: MEC, 1999.

MOREIRA, A. F.; CANDAU, V. M. (Orgs.). Multiculturalismo: diferenças culturais e práticas pedagógicas. Petrópolis, RJ: Vozes, 2008.

OLIVEIRA, Amurabi. A Monocultura Étnico-Racial e a Ecologia das Cores: Olhares póscoloniais sobre a escola. Educação \& Linguagem, v. 17, n. 1; 170-186, jan.-jun. 2014.

QUIJANO, Aníbal. Colonialidade do poder, eurocentrismo e América Latina. In: LANDER, Edgardo (Org.). A Colonialidade do Saber: Eurocentrismo e Ciências Sociais perspectivas latino-americanas. Ciudad Autonoma de Buenos Aires: CLACSO, 2005.

RANCIÈRE, Jacques. As desventuras do pensamento crítico. In: O espectador emancipado. Lisboa: Orfeu Negro, 2010.

SANTOS, Boaventura de Sousa. Uma sociologia das ausências e uma sociologia das emergências. In: A gramática do tempo: por uma nova cultura política. São Paulo: Cortez, 2010.

SILVA, Petronilha Beatriz Gonçalves. Aprender, ensinar e relações etnicorraciais no Brasil. Educação. Porto Alegre/RS, ano XXX, n. 3 (63), p. 489-506, set./dez. 2007.

SILVA, Wilker Solidade da; MARQUES, Eugenia Portela de Siqueira. Descolonizando o ensino: Reflexões sobre a prática docente a partir das Leis 10.639/03 e 11.645/08. Anais Reunião Científica da ANPED. Educação, movimentos sociais e políticas governamentais. 24 a 27 de julho. Curitiba - PR, 2016.

WALSH, Catherine. Desenvolvimento como Buen Vivir: arranjos institucionais e laços (de)coloniais. Novoamerica, n. 126, abr-jun 2010. Acesso em: 26 julho 2018. 